\title{
ENCEFALOPATÍA NO FATAL POR INFLUENZA AH1N1 EN PACIENTE PEDIÁTRICO
}

\author{
María del Carmen Valdivia-Tapia¹, Nilton Yhuri Carreazo ${ }^{2,3}$
}

\begin{abstract}
RESUMEN
Niña de dos años con fiebre y síntomas catarrales que presenta convulsiones focales de hemicuerpo derecho, las cuales persisten adicionándose signos de hipertensión endocraneana. Se identifica Influenza AH1N1 mediante reacción de cadena de polimerasa en hisopado nasofaríngeo. Paciente evoluciona favorablemente con medidas de soporte. No recibió Oseltamivir.

Palabras clave: Encefalitis viral; subtipo H1N1 del virus de la Infuenza A; Oseltamivir; preescolar (fuente: DeCS BIREME).

\section{NON-FATAL CASE OF H1N1 INFLUENZA ENCEPHALOPATHY IN A PEDIATRIC PATIENT}

\begin{abstract}
A 2-year-old girl presented with fever, catarrhal symptoms, and focal right hemispheric seizures that persisted and led to signs of intracranial hypertension. An influenza A H1N1 infection was confirmed via polymerase chain reaction analysis of a nasopharyngeal swab. The patient, who was not treated with oseltamavir, has responded favorably to supportive measures.
\end{abstract}

Key words: Encephalitis, viral; Influenza A virus, H1N1 subtype; Oseltamivir; Child, preschool. (source: MeSH NLM).

\section{INTRODUCCIÓN}

En abril de 2009, el Centro para el Control y la Prevención de Enfermedades (CDC) reportó dos casos de infección humana por un virus de influenza $A$ de origen porcino (H1N1) (1) Un mes después, la Organización Mundial de la Salud (OMS) actualizaba las cifras de la pandemia (2): 1085 pacientes distribuidos en 21 países, de los cuales 26 fallecieron (25 procedentes de México). En nuestro país, hasta el año 2010, se ha reportado 9996 casos confirmados de Influenza AH1N1, con 244 casos letales ${ }^{(3)}$.

El virus de la influenza A suele producir sintomatología respiratoria y hasta en $10 \%$ presenta complicaciones neurológicas diversas; habiéndose reportado en pacientes pediátricos desde convulsiones hasta cuadros de encefalitis y encefalopatía aguda; siendo esta última frecuentemente letal ${ }^{(4)}$. A continuación presentamos el caso de una niña de 2 años 10 meses con encefalopatía aguda por Influenza AH1N1.

\section{REPORTE DE CASO}

Paciente mujer de 2 años 10 meses, procedente de Lima, inmunocompetente, con vacunas incompletas (no recibió inmunización antiinfluenza) y antecedente de varicela en las dos semanas previas al ingreso. Acude a emergencia con historia de un día de síntomas catarrales y fiebre. Aproximadamente dos horas antes del ingreso presenta mirada fija y movimientos de masticación seguidos de convulsiones clónicas focales del hemicuerpo derecho por dos minutos. Al examen físico se encuentra afebril, irritable, no conectada con el entorno, con una escala de Glasgow de 10/15, pupilas isocóricas de $2 \mathrm{~mm}$ fotorreactivas, no rigidez de nuca, tono muscular disminuido.

Hemograma, glucosa, urea, creatinina, electrolitos séricos fueron normales, mientras que la proteína $C$ reactiva fue de $6,4 \mathrm{mg} / \mathrm{dL}$. La radiografía de tórax mostró un aumento de la trama bronquial bilateral y la tomografía espiral multicorte (TEM) cerebral no evidenció alteraciones (Figura 1). El estudio de líquido céfalorraquídeo (LCR) muestra 2 células $/ \mathrm{mm}^{3}$, proteínas $28 \mathrm{mg} / \mathrm{dL}$, glucosa 54 $\mathrm{mg} / \mathrm{dL}$; no observándose microorganismos en la tinción de gram. Coaglutinaciones negativas.

Al ingreso se consideró como diagnóstico "síndrome convulsivo secundario a meningoencefalitis" y se instauró tratamiento con ceftriaxona $100 \mathrm{mg} / \mathrm{kg} / \mathrm{día}$ hasta resultados de cultivos y aciclovir por antecedente de varicela. Por cuadro catarral febril se solicita además, estudio de virus respiratorios por hisopado nasofaríngeo.

\footnotetext{
Servicio de Pediatría. Hospital de Emergencias Pediátricas. Lima, Perú.

Servicio de Cuidados Intensivos Pediátricos. Hospital de Emergencias Pediátricas. Lima, Perú

Escuela de Medicina. Universidad Peruana de Ciencias Aplicadas. Lima, Perú.

Recibido: 16/10/2015 Aprobado: 04/05/2016
} 


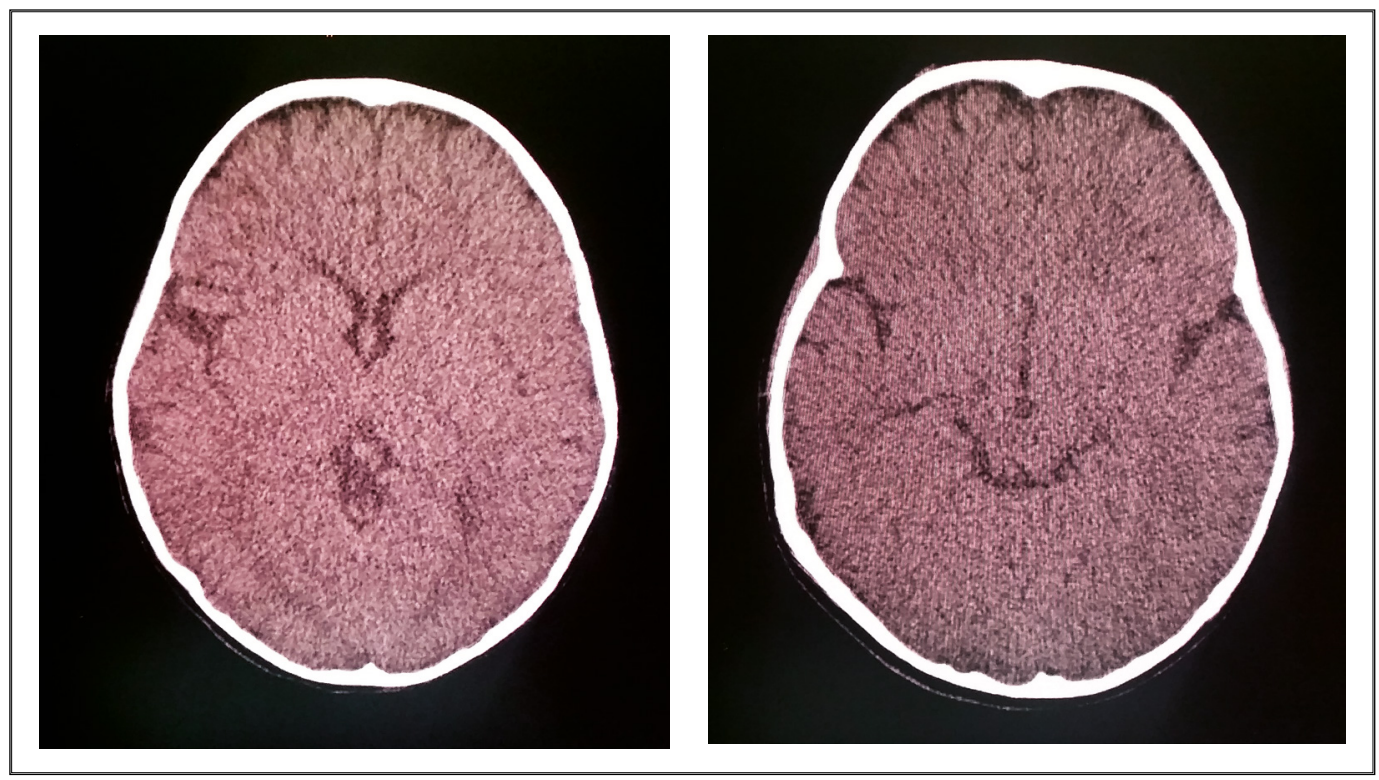

Figuras 1 y 2. Tomografía axial computarizada de cráneo, sin alteraciones significativas

A las $48 \mathrm{~h}$ de internamiento el cuadro febril cede, pero las convulsiones persisten. La resonancia magnética cerebral (RMN) con gadolinio no mostró alteración. A las $72 \mathrm{~h}$ presenta signos de hipertensión endocraneana que requirió uso de manitol $0,5 \mathrm{mg} / \mathrm{kg} / \mathrm{dosis}$. Las convulsiones ceden luego de inicio de fenitoína y ácido valproico. Al cuarto día de hospitalización se evidencia mejoría del sensorio, pero persiste hipotonía generalizada marcada.

Al quinto día llegan resultados de cultivo de LCR, hemocultivo, y estudio de virus herpes simple I y II, enterovirus, varicela zoster, citomegalovirus y virus de Epstein-Barr: todos negativos. Se suspende ceftriaxona, pero se mantiene aciclovir. Se realiza electroencefalograma (EEG) que muestra enlentecimiento difuso.

Al décimo día se recibe resultado de hisopado nasofaríngeo positivo para influenza AH1N1 por RTPCR (reacción de cadena de polimerasa de transcripción reversa). Se suspende aciclovir. La paciente fue dada de alta después de catorce días de hospitalización, aún con moderada hipotonía axial y apendicular.

\section{DISCUSIÓN}

Durante la pandemia por influenza AH1N1 en el año 2009 , las manifestaciones neurológicas fueron descritas hasta en un $10 \%$ de los casos, incluyendo convulsiones, encefalitis, encefalopatía aguda necrotizante, meningitis aséptica y síndrome de Reye ${ }^{(5)}$. La presentación clínica es amplia, incluyendo compromiso de conciencia, hemiplejía, convulsiones, estatus convulsivo, ataxia y disminución de la fuerza muscular; afectando principalmente niños menores de 6 años ${ }^{(6)}$.
El intervalo entre los síntomas respiratorios y la afectación neurológica suele variar entre uno y catorce días, presentando una media de tres días ${ }^{(6)}$. En las pruebas complementarias no se suelen observar hallazgos específicos ${ }^{(7)}$, no obstante valores normales de proteínas en LCR se correlaciona con un buen pronóstico ${ }^{(8)}$.

En los estudios de neuroimagen, las estructuras usualmente afectadas son el tálamo y ganglios basales ${ }^{(9)}$, estableciéndose en función a los cambios cerebrales, visualizados en RMN y TEM, cinco categorías (C) de encefalitis por influenza: normal (C-1), afectación difusa de la corteza cerebral (C-2), edema cerebral difuso (C-3), la afectación simétrica del tálamo (C-4), y la encefalitis focal $(\mathrm{C}-5)^{(10)}$.

Respecto a las alteraciones del EEG se ha descrito el enlentecimiento focal como pista para el diagnóstico precoz ${ }^{(6)}$. Es difícil amplificar el virus por PCR en LCR, lo cual sugiere que el virus de la influenza no presenta un neurotropismo importante, siendo las manifestaciones neurológicas secundarias a la respuesta inflamatoria, liberación de citoquinas (IL-6, TNF-a, IL-10) y apoptosis en el sistema nervioso central ${ }^{(11)}$. Por lo tanto, en la mayoría de los pacientes con afectación neurológica, solo es posible aislar el virus de la influenza $A$ en muestras de exudado nasofaríngeo.

La evolución y pronóstico depende del estado inmunitario del paciente y de las complicaciones asociadas ${ }^{(7)}$. El espectro de secuelas neurológicas incluyen cuadriparesia ${ }^{(12)}$, hemiplejía e hipertonía de extremidades ${ }^{(13)}$. En relación con el uso de oseltamivir, se han descrito casos con 
evolución favorable sin el uso del antiviral ${ }^{(14) ; ~ a s i ́ ~ c o m o ~}$ pacientes con recuperación completa, en los cuales se administró oseltamivir ${ }^{(15)}$. Sin embargo, esto último podría ser atribuido también a la autolimitación propia de la enfermedad (10). En este sentido, es de suma importancia la prevención, mediante la vacunación con el fin de disminuir la incidencia de influenza $A H 1 N 1$, y sus posibles complicaciones neurológicas.

Nuestro caso coincide con los descritos previamente en la literatura. La paciente de dos años, tras un cuadro catarral de un día, presenta convulsiones y alteración del estado de conciencia. Al igual que en otros casos el LCR fue normal, y el EEG mostraba un trazado lento. La neuroimagen fue normal (categoría C1) y se logró aislar el virus en hisopado nasofaríngeo por RT-PCR, más no en LCR. Recibió un ciclo de aciclovir de 10 días hasta realizado el diagnóstico, no utilizándose oseltamivir. Con una evolución lentamente favorable, fue dada de alta a los 14 días de hospitalización.
La encefalitis por influenza AH1N1, es una enfermedad que se debe sospechar ante pacientes con cuadros catarrales previos y afectación neurológica compatible, en los cuales no se haya aislado agente etiológico. Hasta el momento la eficacia del oseltamivir en complicaciones neurológicas por influenza $\mathrm{AH} 1 \mathrm{~N} 1$ no ha sido claramente determinada; describiéndose casos -como el presente- en los cuales sin su uso se presenta una ostensible recuperación. Considerando la dificultad en predecir que paciente presentará complicaciones, es fundamental incentivar la prevención mediante la vacunación disponible en el esquema nacional de inmunizaciones.

Contribuciones de autoría: NYC realizó la concepción y diseño del artículo. MVT realizó la recolección de datos. NYC y MVT participaron en la redacción, revisión y aprobación de la versión final.

Fuente de financiamiento: el estudio fue autofinanciado.

Conflictos de interés: los autores declaran no tener ningún conflicto de interés.

\section{REFERENCIAS BIBLIOGRÁFICAS}

1. Novel Swine-Origin Influenza A (H1N1) Virus Investigation Team, Dawood FS, Jain S, Finelli L, Shaw MW, Lindstrom S, et al. Emergence of a novel swine-origin influenza A (H1N1) virus in humans. N Engl J Med 2009;360(25):2605-15. doi: 10.1056/NEJMoa0903810.

2. Influenza A (H1N1) - update 14 . [Internet] Geneva: World Health Organization, 2009 [Citado el 23 de septiembre de 2015 sept 23]. Disponible en: http://www.who.int/ csr/don/2009_05_04a/en/

3. Dirección General de Epidemiología. Perú, Ministerio de Salud. Sala situacional del 9 de agosto de 2010 [Internet]. Lima: DGE/MINSA; 2010 [Citado 2015, sept 23]. Disponible en http://www.dge.gob.pe/influenza/flu/ sala/Sala_pandemia_09-08-2010.pdf

4. Okumura A, Nakagawa S, Kawashima $\mathrm{H}$, Morichi S, Muguruma T, Saito O, et al. Severe form of encephalopathy associated with 2009 pandemic influenza A (H1N1) in Japan. J Clin Virol.2013;56(1):25-30. doi: 10.1016/j. jcv.2012.10.007.

5. Newland JG, Laurich VM, Rosenquist AW, Heydon K, Licht DJ, Keren R, et al. Neurologic complications in children hospitalized with influenza: characteristics, incidence, and risk factors. J Pediatr. 2007;150(3):306-10.

6. Amin R, Ford-Jones E, Richardson
SE, MacGregor D, Tellier R, Heurter $\mathrm{H}$, et al. Acute childhood encephalitis and encephalopathy associated with influenza: a prospective 11-year review. Pediatr Infect Dis J. 2008;27(5):390-5. doi: 10.1097/INF.0b013e31816507b2.

7. Cebrián I, Morell C, Centelles I, Esparza MA, Jovani C, Romagrosa-Sánchez B. Encefalitis vírica y convulsiones refractarias por gripe A en época no estacional. Rev Pediatr Aten Primaria. 2015;17:57-60.

8. Mastroyianni SD, Gionnis D, Voudris K, Skardoutsou A, Mizuguchi M. Acute necrotizing encephalopathy of childhood in non-Asian patients: report of three cases and literature review. J Child Neurol. 2006;21(10):872-9

9. Zhao C, Gan Y, Sun J. Radiographic study of severe influenza AH1N1 disease in children. Eur J Radiol. 2011;79(3):447-51. doi: 10.1016/j. ejrad.2010.09.015.

10. Kulkarni R, Kinikar A. Encephalitis in a child with H1N1 infection: First case report from India. J Pediatr Neurosci. 2010;5(2):157-9. doi: 10.4103/18171745.76119 .

11. Hasegawa $S$, Matsushige $T$, Inoue $\mathrm{H}$, Shirabe K, Fukano R, Ichiyama T. Serum and cebrospinal fluid cytokine profile of patients with 2009 pandemica $\mathrm{H} 1 \mathrm{N1}$ influenza virus associated encephalopathy. Cytokine. 2011;54(2):167-72. doi: 10.1016/j. cyto.2011.01.006

12. Ozkale Y, Erol I, Ozkale M, Demir S, Alehan F. Acute disseminated encephalomyelitis associates with influenza AH1N1 infection. Pediatr Neurol. 2012;47(1):62-4. doi: 10.1016/j.pediatrneurol.2012.03.019.

13. Chen YC, Lo CP, Chang TP. Novel Influenza A (H1N1) associated encephalopathy/encephalitis with severe neurological sequelae and unique Image features - A case report. J Neurol Sci. 2010;298(1-2):110-3. doi: 10.1016/j. jns.2010.09.010.

14. Locuratolo N, Mannarelli D, Colonnese C, Pauletti C, Antonaci L, Ferretti $\mathrm{G}$ et al. Unusual posterior reversible encephalopathy syndrome in a case of influenza AH1N1 infection. J Neurol sci. 2012;321(1-2):114-6. doi: 10.1016/j.jns.2012.07.063.

15. Choi SY, Jang SH, Kim JO, Ihm CH, Lee MS, Yoon SJ. Novel Swine-Origin Influenza A (H1N1) Viral Encephalitis. Yonsei Med J. 2010;51(2):291-2. doi: 10.3349/ymj.2010.51.2.291.

Correspondencia: Nilton Yhuri Carreazo Dirección: Av. General Garzón 685 Lima 11. Lima, Perú

Correo electrónico:yhuroc@gmail.com 